\title{
ОБ ИНТЕРПРЕТАЦИИ ДАННЫХ СТАТИЧЕСКОГО ЗОНДИРОВАНИЯ ГРУНТОВ
}

\author{
Латыпов Айрат Исламгалиевич', \\ airatlat@mail.ru \\ яббарова Екатерина Николаевна', \\ yabbarova.en@mail.ru \\ 1 Казанский (Приволжский) федеральный университет, \\ Россия, 420008, г. Казань, ул. Кремлевская, 4/5.
}

\begin{abstract}
Актуальность исследования обусловлена все более возрастающим использованием метода статического зондирования грунтов, изменением требований к проектированию фундаментов в современном строительстве, а также выявленным существенным расхождением физико-механических характеристик грунтов, определенных по данным статического зондирования согласно таблицам СП 11-105, и данных лабораторных испытаний.

Цель: выполнение сравнительного анализа данных лабораторных исследований с данными статического зондирования на исследуемой территории.

Объекты: грунтовое основание фундаментов жилого комплекса по ул. Родина г. Казани.

Методы: анализ отечественного и зарубежного опыта, статическое зондирование грунтов, лабораторные исследования физико-механических свойств грунтов, статистическая обработка результатов испытаний.

Результаты. На примере площадки строительства комплекса жилых 9-25-ти этажных домов в г. Казани показана невозможность использования таблиц СП 11-105 для определения механических характеристик ряда грунтов. Данный вывод сделан на основании обработки результатов 125 точек статического зондирования, пройденных до глубин 20 м, проходки 59 скважин глубиной до 40 м, а также лабораторных испытаний образцов грунта с определением прочностных и деформационных свойств. Сравнительный анализ данных полевых и лабораторных исследований для различных инженерно-геологических элементов на исследуемой площадке показал, что значения прочностных и деформационных характеристик грунтов, определенных с помощью метода статического зондирования, получаются существенно завышенными, а несущая способность свай заниженной. Решить данную проблему предлагается с помощью создания территориальных строительных норм в области статического зондирования грунтов для г. Казани и Республики Татарстан. Это позволит повысить точность инженерно-геологических изысканий и увеличить экономическую рентабельность строительства.
\end{abstract}

\section{Ключевые слова:}

Грунт, статическое зондирование, территориальные строительные нормы, Казань, Республика Татарстан.

\section{Введение}

На сегодняшний день город Казань является одним из крупнейших промышленных, культурных и торговых центров в Поволжье. В городе ведется активное строительство новых и реконструкция существующих районов, строятся мосты, транспортные развязки и тоннели, сооружения метрополитена. Также наблюдается тенденция к освоению территорий со сложными инженерногеологическими условиями. Активно застраиваются и другие города Республики Татарстан. Это обуславливает появление новых, все более сложных требований, предъявляемых проектными организациями к изыскателям.

Основные закономерности формирования инженерно-геологических условий города Казани систематизированы в работе [1]. Позднее, начиная с 2008 г., коллективом кафедры общей геологии и гидрогеологии Казанского федерального университета совместно с ОАО «Казанский трест инженерно-строительных изысканий» на основании обобщения данных более чем 1000 скважин была создана постоянно действующая модель (ПДМ) геологической среды г. Казани [2].

Каждый элемент ПДМ имеет строгую привязку как в плане, так и по глубине, связанную с ним базу данных физико-механических свойств грунтов, их генетическую привязку, положение относи- тельно уровня грунтовых вод и т. д. Возможности ПДМ позволяют проводить сортировку инженерно-геологических элементов по какому-либо заданному признаку, выполнять статистическую обработку, проводить интерполяции, пространственные операции и т. п. Это позволило построить серию инженерно-геологических, геоморфологических, гидрогеологических карт, карт развития опасных геологических процессов и т. п. ПДМ неоднократно была использована для решения различных практических задач $[3,4]$.

На момент создания ПДМ задачи внесения в ее структуру данных полевых исследований не ставилось. Вместе с тем в настоящий момент, согласно действующим нормативным документам в строительстве СП 22.13330 [5] для зданий I и II уровня ответственности, значения лабораторных характеристик необходимо уточнять результатами полевых исследований. Наиболее популярным полевым методом при проведении инженерно-геологических изысканий является метод статического зондирования грунтов. Ограниченность применения данного метода для определения физико-механических характеристик обусловлена тем, что они рассчитываются на основании корреляционных таблиц (приложение И, часть I, СП 11-105 [6]), составленных для всей территории Российской Федерации. Это приводит к тому, что расхождение 
между результатами полевых и лабораторных исследований имеет недопустимые границы, которые выявлены в работах И. Рыжкова и О. Исаева [7], Р. Зиангирова и В. Каширского [8], Г. Болдырева [9] и др.

Градостроительным кодексом Российской Федерации субъектам федерации предоставлено право разрабатывать и утверждать территориальные строительные нормы (ТСH), которые составляются с учетом природно-климатических, социально-демографических, экономических и иных особенностей субъекта Российской Федерации.

На сегодняшний день создание и использование ТСН признано наиболее эффективным способом развития инженерных изысканий, позволяющим повысить их достоверность, снизить трудоемкость и стоимость.

Подобный подход активно используется как в России, так и за рубежом.

Так, Г. Болдырев, Г. Болдырев и др. предложили для групп, объединяющих грунты различного вида, происхождения и возраста, использовать различные корреляционные уравнения, отличающиеся номенклатурой входящих в них переменных, величиной коэффициентов, наличием нелинейных зависимостей $[10,11]$. Р. Зиангиров и В. Каширский предлагают использовать для моренных суглинков зависимость штампового модуля деформации от лобового сопротивления погружению зонда [8]. Г. Болдырев, В. Барвашов и др. в настоящий момент разрабатывают новый подход к оценке инженерно-геологических условий, при котором метод статического зондирования грунтов используется для построения моделей неоднородности грунтового массива [12].

Зарубежные исследования в большинстве посвящены проблеме поиска корреляционных уравнений между сопротивлением погружению зонда $q_{c}$ и деформационными характеристиками, в частности, модулем деформации $E_{\text {oed }}$.

Так, Т. Lunne, H. Christophersen предложили следующую зависимость для компрессионного модуля деформации нормально консолидированных молодых и несцементированных силикатных песков [13]:

$$
E_{\text {oed }}=4 q_{c} \text { для } q_{c}<10 \mathrm{M \Pi а.}
$$

K. Senneset et al. нашли зависимость между скорректированным значением лобового сопротивления зонда и компрессионным модулем деформации, используя корреляционный коэффициент $\alpha_{\text {oed }}$ [14].

A. Meigth утверждает, что $\alpha_{\text {oed }}$ находится в диапазоне от 2 до 8 [15], в то время как Р. Mayne говорит о том, что этот коэффициент равен 8 [16].

В зависимости от вида грунта в работе G. Sanglerat коэффициент $\alpha_{\text {оеd }}$ изменяется от 1 до 8 при лобовом сопротивлении в диапазоне от 0,7 до 2,0 МПа [17].

G. Jones, E. Rust нашли для аллювиальных глинистых грунтов Южной Африки значение коэффициента $\alpha_{\text {oed }}=2,75 \pm 0,55$ [18].
G. Sanglerat et al. показал, что коэффициент $\alpha_{0 \text {. }}$ ed зависит от числа пластичности и содержания природной влажности в широком диапазоне глинистых и органо-минеральных грунтов, основываясь на данных измерений $q_{c}$ [19].

Корреляция, предложенная F. Kulhawy, P. Maуnе, имеет более общую форму и не зависит от вида грунта или величины лобового сопротивления, и имеет вид [20]:

$$
E_{\text {oed }}=8,25\left(q_{t}-\sigma_{v o}\right),
$$

где $q_{t}$ - лобовое сопротивление; $\sigma_{v o}$ - напряжение от собственного веса грунта.

Все это говорит о том, что актуальность использования метода статического зондирования для решения самого широкого круга инженерно-геологических и геотехнических задач очень высока.

\section{Область исследования}

Авторами в настоящий момент начата работа по включению в ПДМ г. Казани данных статического зондирования грунтов с построением корреляционных зависимостей между лабораторными и полевыми определениями характеристик грунтов, что позволит в перспективе перейти к созданию территориальных строительных норм по статическому зондированию грунтов для Республики Татарстан.

Для апробации был выбран участок по ул. Родины в г. Казани с проектируемой и действующей застройкой (рис. 1). В 2016-2017 гг. на участке было пробурено более 59 скважин глубиной до 40 м, пройдено 125 точек статического зондирования (С3), выполнен комплекс лабораторных определений физико-механических свойств грунтов.

В геоморфологическом отношении исследуемая территория расположена в пределах III надпойменной террасы левобережья р. Волга. Площадь участка составляет 0,21 км². Поверхность участка относительно ровная, характеризуется абсолютными отметками 91,1-92,3 м, с незначительным уклоном с востока на запад.

На исследуемой территории был запроектирован и в настоящий момент возводится жилой комплекс, включающий 19 домов переменной этажности (от 9 до 25 этажей), школа, детский сад и объекты инфраструктуры. Схема расположения контуров зданий и пройденных инженерно-геологических скважин показана на рис. 2.

В геологическом строении площадки изысканий принимают участие современные техногенные отложения, среднечетвертичные аллювиально-делювиальные отложения, представленные суглинками и глинами полутвердыми и тугопластичными, суглинками и супесями твердыми, супесью пластичной, а также песком пылеватым, мелким и средней крупности. Схематический разрез территории показан на рисунке рис. 3 .

Основной водоносный горизонт в пределах исследуемого участка залегает на глубинах 29-30 м от поверхности и приурочен к неоген-четвертичному аллювиальному комплексу. Состав вод преиму- 


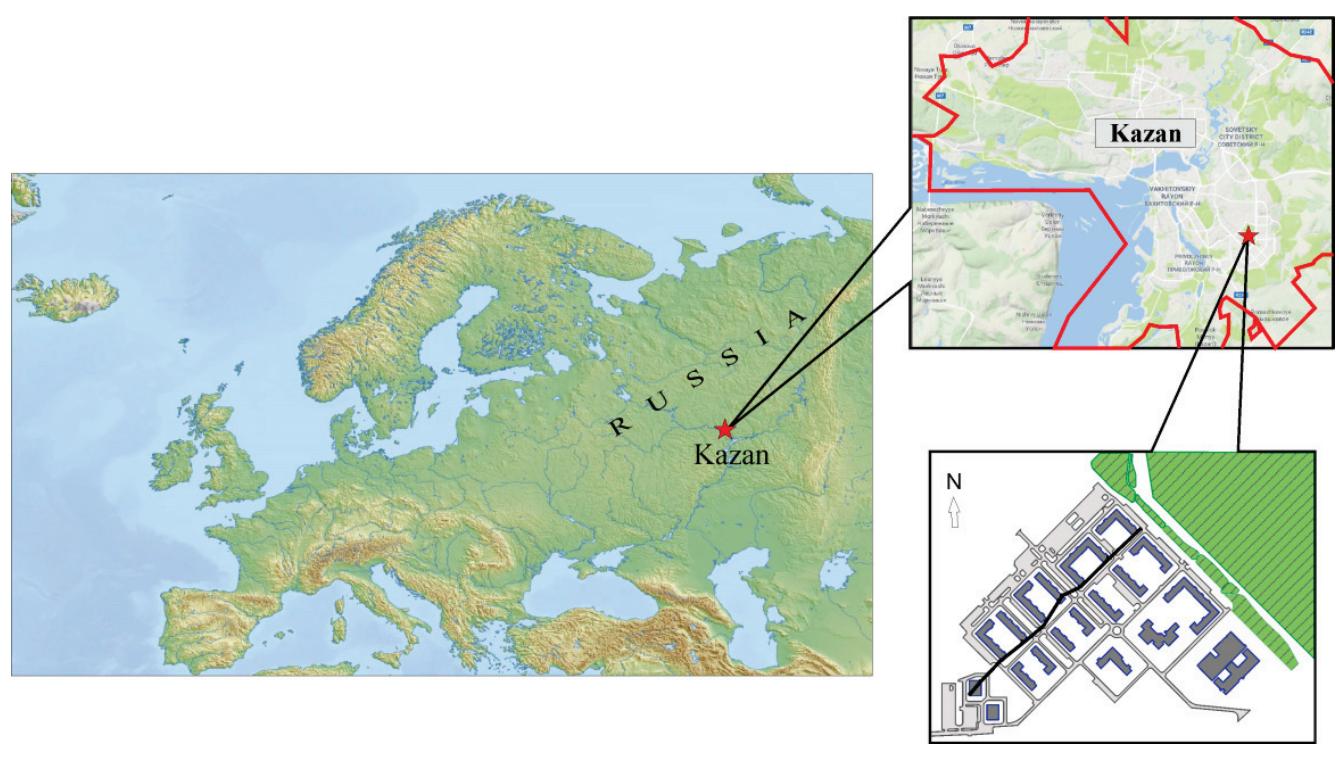

Pис.1. Схема расположения исследуемого участка

Fig. 1. Location of the object under study

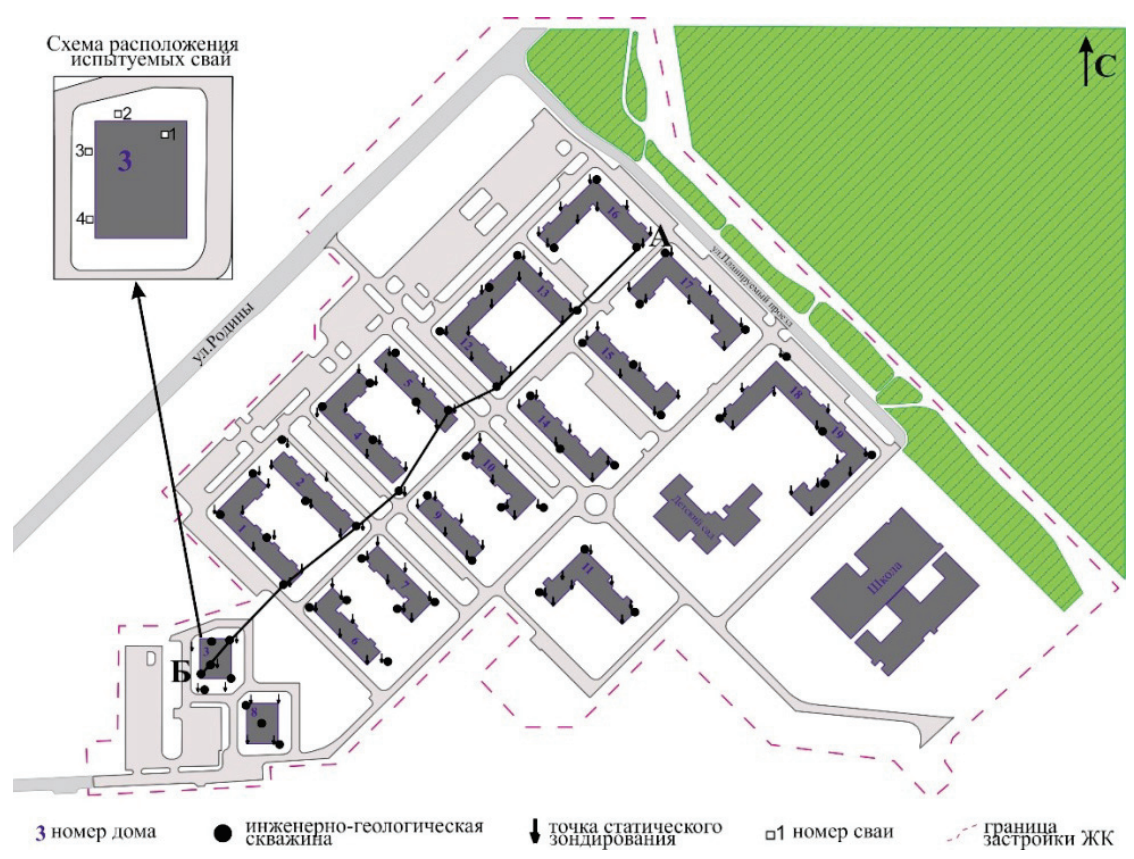

Pис. 2. Схема расположения элементов застройки и точек полевых работ

Fig. 2. Scheme of location of the buildings and the points of field work

щественно хлоридно-гидрокарбонатный. Локально развита верховодка.

На исследуемой площадке было пройдено 125 точек статического зондирования, на основании которых, согласно Приложению И, СП 11-105, было выполнено определение угла внутреннего трения, удельного сцепления и модуля деформации грунтов для каждого инженерно-геологического элемента. Эти же механические характеристики были определены в лабораторных условиях при испытаниях на компрессионное сжатие и одноплоскостной срез. Результаты определений по полевым и лабораторным данным приведены в табл. 1.

Процентное расхождение между лабораторными и полевыми определениями сведено в табл. 2.

Как можно увидеть, имеет место существенное расхождение значений модуля деформации, угла внутреннего трения и удельного сцепления.

Причиной подобного расхождения является, как отмечалось выше, наличие в таблицах нормативных документов значений, полученных для всей территории РФ и, как следствие, отсутствие учета региональных факторов. 


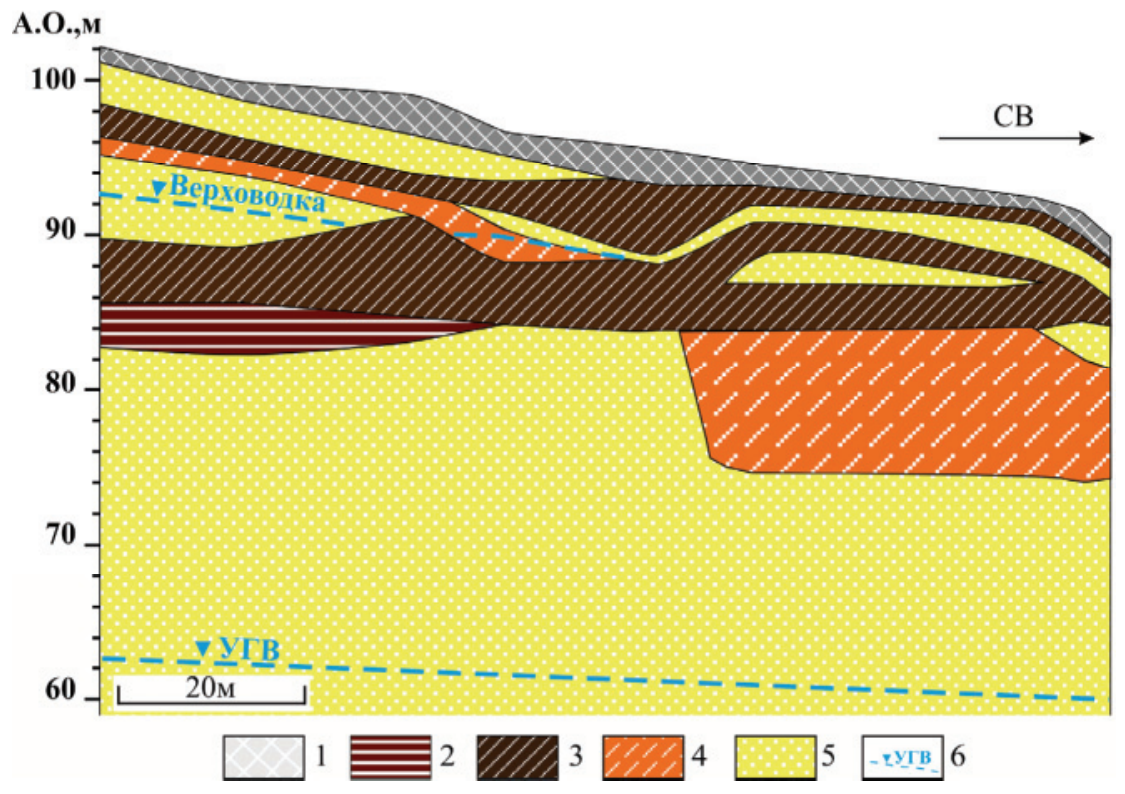

Рис.3. Схематический инженерно-геологический разрез по линии А-Б (положение линии разреза показано на рис. 2). 1) насыпной грунт; 2) глина тугопластичная, ИГЭ 2б; 3 ) суглинок тугопластичный, ИГЭ 3б; 4) супесь твердая, ИГЭ 4а; 5 ) песок мелкий, ИГЭ $6 ; 6)$ уровень грунтовых вод

Fig. 3. Schematic engineering-geological section along the A- 5 line (the section line location is shown in Fig. 2). 1) fill-up soil; 2 ) firm-stiff clay EGE 2b;3) firm-stiff loam EGE 3b;4) sandy loam EGE 4a; 5 ) fine grained sand EGE 6;6) groundwater level

таблица 1. Значения механических характеристик грунтов по лабораторным данныл и результатал статическо го зондирования

Table 1. Values of mechanical characteristics of soils according to laboratory tests and the results of cone penetration tests

\begin{tabular}{|c|c|c|c|c|c|c|c|}
\hline \multirow{2}{*}{ 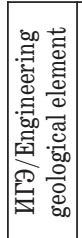 } & \multirow[t]{2}{*}{$\begin{array}{c}\text { Наименование грунта } \\
\text { Name of soil }\end{array}$} & \multicolumn{3}{|c|}{$\begin{array}{c}\text { По лаборатор- } \\
\text { ным данным } \\
\text { According to } \\
\text { laboratory tests }\end{array}$} & \multicolumn{3}{|c|}{$\begin{array}{c}\text { По данным С3 } \\
\text { According to } \\
\text { Cone Penetration } \\
\text { Tests } \\
\text { (CП 11-105) }\end{array}$} \\
\hline & & $\begin{array}{c}E, \\
\text { МПа }\end{array}$ & $\varphi,{ }^{\circ}$ & $\begin{array}{c}c \\
\mathrm{M} \\
\mathrm{Ma}\end{array}$ & $\begin{array}{c}E, \\
\text { MПа }\end{array}$ & $\varphi,{ }^{\circ}$ & $\begin{array}{c}c, \\
\text { МПа }\end{array}$ \\
\hline $\begin{array}{l}2 \mathrm{a} \\
2 \mathrm{a}\end{array}$ & $\begin{array}{l}\text { Глина полутвердая } \\
\text { Stiff clay }\end{array}$ & 45,2 & 13,00 & 0,06 & 38,7 & 23,02 & 0,05 \\
\hline $\begin{array}{l}2 \sigma \\
2 b\end{array}$ & \begin{tabular}{|l|} 
Глина тугопластичная \\
Firm-stiff clay
\end{tabular} & 18,3 & 11,01 & 0,02 & 35,4 & 21,09 & 0,05 \\
\hline $\begin{array}{l}3 \mathrm{a} \\
3 \mathrm{a}\end{array}$ & $\begin{array}{l}\text { Суглинок полутвердый } \\
\text { Stiff clay loam }\end{array}$ & 28,2 & 15,21 & 0,05 & 39,5 & 25,37 & 0,04 \\
\hline $\begin{array}{l}36 \\
3 \mathrm{~b}\end{array}$ & $\begin{array}{l}\text { Суглинок тугопластичный } \\
\text { Firm-stiff clay loam }\end{array}$ & 14,9 & 12,43 & 0,03 & 19,0 & 21,88 & 0,03 \\
\hline $\begin{array}{l}3 \mathrm{~B} \\
3 \mathrm{c}\end{array}$ & $\begin{array}{l}\text { Суглинок мягкопластичный } \\
\text { Soft-firm clay loam }\end{array}$ & 11,4 & 9,82 & 0,02 & 16,2 & 20,48 & 0,02 \\
\hline $\begin{array}{l}4 \mathrm{a} \\
4 \mathrm{a}\end{array}$ & \begin{tabular}{|l|} 
Супесь твердая \\
Very stiff sandy loam
\end{tabular} & 26,9 & 13,00 & 0,01 & \multirow{2}{*}{\multicolumn{3}{|c|}{$\begin{array}{c}\text { Значения } \\
\text { отсутствуют } \\
\text { No values }\end{array}$}} \\
\hline $\begin{array}{l}46 \\
4 \mathrm{~b}\end{array}$ & \begin{tabular}{|l|} 
Супесь пластичная \\
Very soft-stiff sandy loam
\end{tabular} & 21,3 & 16,00 & 0,01 & & & \\
\hline
\end{tabular}

Дополнительно необходимо добавить, что для ИГЭ 4а и 4 б в нормах [6] вообще отсутствует возможность определения характеристик грунтов по данным статического зондирования.

С подобной проблемой изыскатели Республики Татарстан сталкиваются практически при проведении всех изысканий, связанных с необходимо- стью интерпретации данных статического зондирования. Большинство изыскателей отмечает, что значения механических характеристик, полученных при зондировании, получается всегда выше, чем полученных прямыми лабораторными методами. Это подтверждается и изучением рассматриваемого жилого массива. В нашем случае (табл. 1) имеет место завышение по модулю деформации до $93,4 \%$, по углу внутреннего трения до $108 \%$, по удельному сцеплению до 150 \% (табл. 2). Очевидно, говорить в таком случае о применимости метода статического зондирования для определения или уточнения прочностных и деформационных параметров грунтов не приходится.

Таблица 2. Сравнительный анализ значений механических характеристик

Table 2. Comparative analysis of values of mechanical characteristics

\begin{tabular}{|c|c|c|c|c|}
\hline \multirow{2}{*}{$\begin{array}{c}\text { ИГЭ } \\
\text { Engineering } \\
\text { geological } \\
\text { element }\end{array}$} & \multirow{2}{*}{$\begin{array}{l}\text { Наименование } \\
\text { Name of soil }\end{array}$} & \multicolumn{3}{|c|}{$\begin{array}{l}\text { Pacхождение, \% } \\
\text { Divergence, \% }\end{array}$} \\
\hline & & $E$, МПа & $\varphi,{ }^{\circ}$ & $c$, МПа \\
\hline $\begin{array}{l}2 \mathrm{a} \\
2 \mathrm{a}\end{array}$ & $\begin{array}{l}\text { Глина полутвердая } \\
\text { Stiff clay }\end{array}$ & 14,3 & 77 & 16,6 \\
\hline $\begin{array}{l}26 \\
2 b\end{array}$ & $\begin{array}{l}\text { Глина тугопластичная } \\
\text { Firm-stiff clay }\end{array}$ & 93,4 & 91,5 & 150 \\
\hline $\begin{array}{l}3 \mathrm{a} \\
3 \mathrm{a}\end{array}$ & $\begin{array}{l}\text { Суглинок полутвердый } \\
\text { Stiff clay loam }\end{array}$ & 40 & 66,8 & 20 \\
\hline $\begin{array}{l}36 \\
3 b\end{array}$ & $\begin{array}{l}\text { Суглинок тугопластичный } \\
\text { Firm-stiff clay loam }\end{array}$ & 27,5 & 76 & Совпадают \\
\hline $\begin{array}{l}3 \mathrm{~B} \\
3 \mathrm{c}\end{array}$ & $\begin{array}{l}\text { Суглинок мягкопластичный } \\
\text { Soft-firm clay loam }\end{array}$ & 42,1 & 108 & Match up \\
\hline
\end{tabular}




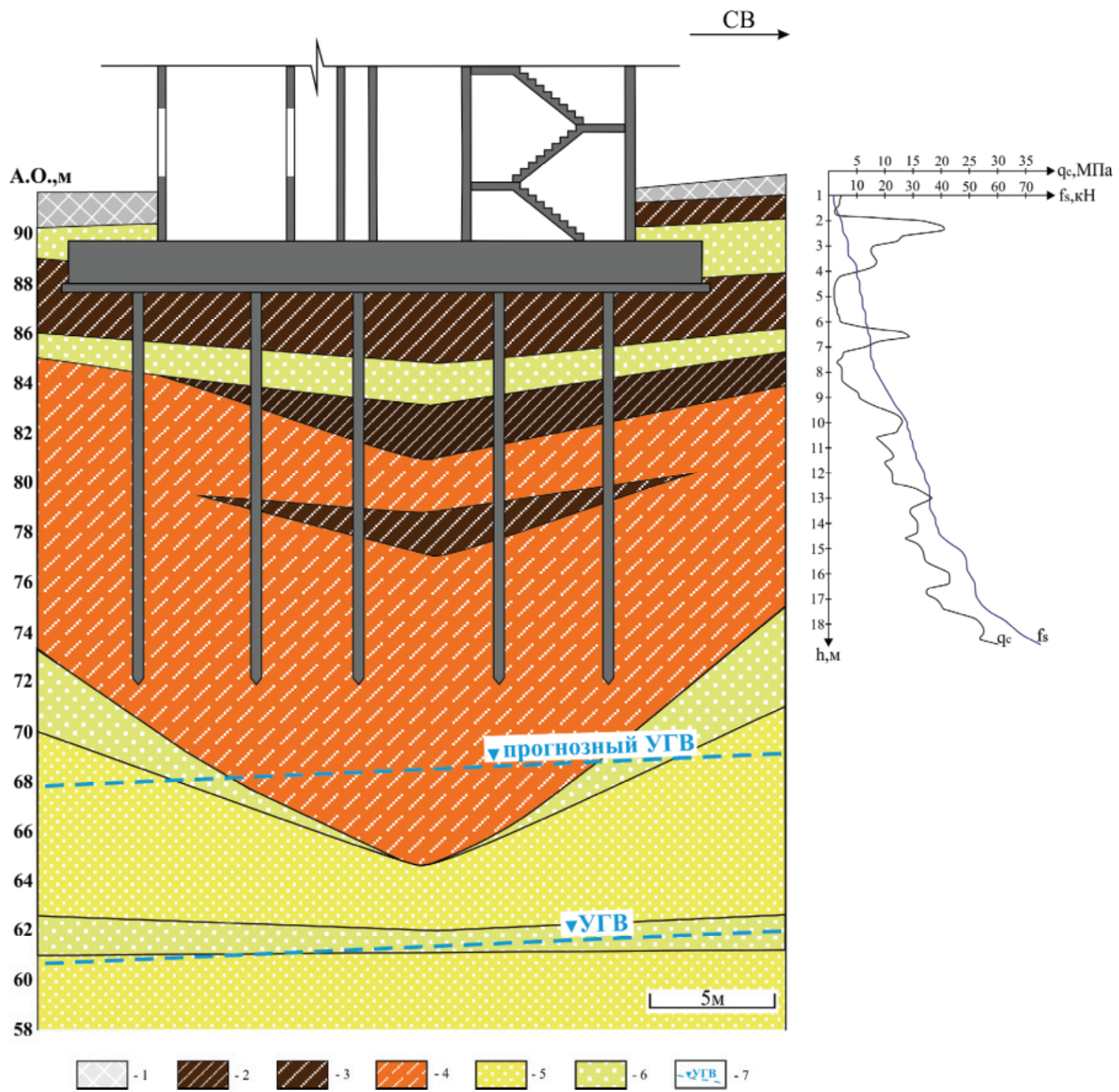

Pис.4. Схема свайно-плитного фундамента жилого дома № 3 (расположение дома показано на рис. 2): 1) насыпной грунт; 2) суглинок полутвердый, ИГЭ За; 3) суглинок тугопластичный, ИГЭ 3б; 4) супесь пластичная, ИГЭ 4б; 5) песок мелкий, ИГЭ 6;6) песок средней крупности, ИГЭ 7; 7) уровень грунтовых вод

Fig. 4. Scheme of the pile-plate foundation of the residential house № 3 (location of the residential house is shown in Fig. 2): 1) fill-up soil; 2) stiff loam EGE 3a;3) firm-stiff loam EGE 3b;4) very soft-stiff sandy loam EGE 4b;5) fine grained sand EGE 6;6) medium sand EGE 7;7) groundwater level

Кроме выше обозначенной также существует проблема определения несущей способности свай на основании данных статического зондирования грунтов. В качестве примера можно привести 25-этажный дом № 3 , местоположение которого показано на рис. 2. Принятый проектом тип фундамента - свайно-плитный. Схема фундамента приведена на рис. 4.

Ниже приводятся результаты определения несущей способности одиночной сваи $F_{d}$ расчетным способом и по результатам статического зондирования.

В соответствии с СП 24.13330 «Свайные фундаменты» несущая способность сваи $F_{d}$, работающей на сжимаемую нагрузку:

$$
\begin{gathered}
F_{d}=\gamma_{c}\left(\gamma_{c R} R A+U \sum f_{i} h_{i} \gamma_{c f}\right)= \\
=1 \cdot(1 \cdot 12600 \cdot 0.09 \cdot 1.2 \cdot(63+227+280+650) \cdot 1)= \\
=2234.4 \mathrm{KH},
\end{gathered}
$$

где $y_{c}$ - параметр, характеризующий условия работы сваи в грунтовом основании; $R$-сопротивление грунта, залегающего непосредственно под острием сваи, кПа; $A$ - площадь поперечного сечения сваи, $\mathrm{M}^{2} ; y_{c R}{ }^{-}$ параметр, характеризующий условия работы грунтового основания под острием сваи; $U$ - периметр поперечного сечения сваи, м; $f_{i}$ - сопротивление $i$-го слоя грунтового основания на контакте с боковой по- 

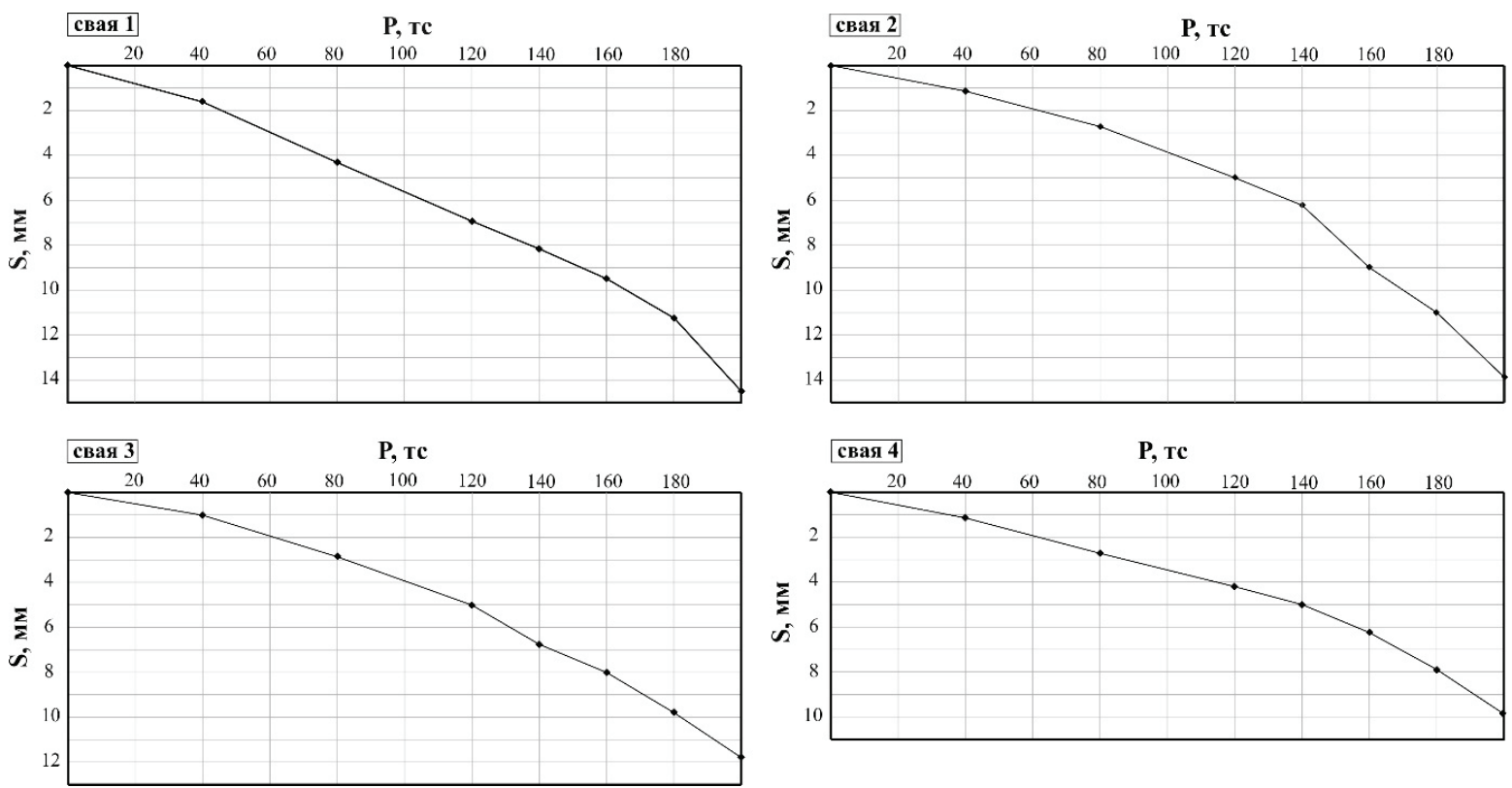

Рис. 5. Графики испытаний свай статической нагрузкой (схема расположения испытуемых свай показана на рис. 2)

Fig. 5. Diagrams of pile tests under static load (the location of the piles is shown in Fig. 2)

верхностью сваи, кПа; $h_{i}$ - толщина $i$-го слоя грунта на контакте с боковой поверхностью сваи, м.

Несущая способность сваи $F_{d}$ по результатам статического зондирования:

$$
\begin{gathered}
F_{d}=\frac{\gamma_{c}\left(R_{s} A+f h U\right)}{\gamma_{g}}= \\
\frac{1 \cdot(6350 \cdot 0,09 \cdot 46,5 \cdot 20 \cdot 1,2)}{1}=1687,5 \mathrm{\kappa H},
\end{gathered}
$$

где $R_{S}$ - максимально допустимое сопротивление грунта под острием сваи, кПа; $f$ - среднее значение максимально допустимого сопротивления грунта на боковой поверхности сваи, кПа; $h$ - расстояние от поверхности до нижнего конца сваи, м.

Очевидно существенное расхождение между двумя методами. Общеизвестно, что результаты, полученные методом статического зондирования, должны иметь более близкие к реальным значения. Однако полевые испытания свай (рис. 5) показали, что несущая способность свай во всех испытаниях существенно выше 2000 кН, тогда как по результатам статического зондирования в исследуемой точке $F_{d}=1688$ кН.

Все это говорит о том, что существующие корреляционные зависимости, на которых основана

\section{СПИСОК ЛИТЕРАТУРЫ}

1. Жаркова Н.И. Закономерности формирования инженерно-геологических условий г. Казани: автореф. дис. ... канд. геол.-минерал. наук. - Екатеринбург, 2006. - 22 с.

2. Гидрогеологические и инженерно-геологические условия города Казани / А.И. Шевелев, Н.И. Жаркова, И.А. Хузин, С.И. Поляков, Р.К. Галеев, И.А. Серебренникова, А.И. Латы- обработка данных статического зондирования на территории Республики Татарстан, требуют корректировки.

\section{Заключение}

Существенное расхождение физико-механических характеристик грунтов, определенных по данным статического зондирования согласно таблицам СП 11-105, с данными прямых лабораторных испытаний показывает практическую неприменимость метода С3 как для уточнения значений прочностных и деформационных свойств грунтов, так и для расчета несущей способности свай на территории Республики Татарстан.

Исследования, проведенные на площадке строительства комплекса жилых домов по ул. Родины г. Казани, показали, что значения прочностных и деформационных характеристик, полученных с помощью метода С3, получаются, как правило, существенно завышенными, а несущая способность свай заниженной.

Для решения данной проблемы наиболее перспективным является создание территориальных строительных норм для г. Казань и Республики Татарстан, что позволит повысить точность инженерно-геологических изысканий и увеличить экономическую рентабельность строительства.

пов, И.С. Нуриев, Ю.Р. Ахиярова, М.И. Мухамедшина. - Казань: Изд-во Казан. ун-т, 2012. - 236 с.

3. Создание постоянно действующей модели геологической среды г. Казани для решения различных инженерно-геологических задач / Н.И. Жаркова, А.И. Латыпов, А.И. Шевелёв, И.А. Хузин // Современные проблемы гидрогеологии, инженерной геологии и гидрогеоэкологии Евразии: Материалы Все- 
российской конференции. - Томск: ТПУ, 2015. - Т. II. C. $329-336$.

4. Latypov A., Zharkova N., Voznesensky E. Zoning of the Kazan City territory by the stability of foundation soil during dynamic impact // Advances and Trends in Engineering Materials and their Applications. - 2017. - V. 2017-June. - P. 45-51.

5. СП 22.13330. Основания зданий и сооружений. - М.: Минрегион России, 2016. - 162 с.

6. СП 11-105. Инженерно-геологические изыскания для строительства. Ч. І. - М.: Изд-во ПНИИИС Госстроя России, 1997. - 47 с.

7. Рыжков И.Б., Исаев 0.Н. Статическое зондирование грунтов. М.: Изд-во АСВ, 2010. - 496 с.

8. Зиангиров Р.С., Каширский В.И. Оценка деформационных свойств дисперсных грунтов по данным статического зондирования // Основания, фундаменты и механика грунтов. 2005. - № 1. - C. 12-16.

9. Болдырев Г.Г. Руководство по интерпретации данных испытаний методами статического и динамического зондирования для геотехнического проектирования. - М.: Изд-во 000 «Прондо», 2017. -476 с.

10. Болдырев Г.Г. Численное моделирование статического и бурового зондирования грунтов // Геотехника. - 2016. - № 4. - С. 58-74.

11. Болдырев Г.Г., Каширский В.И., Мельников А.В. Об интерпретации данных статического зондирования грунтов // Геотехника. - 2016. - № 5. - С. 10-15.

12. Комплексная технология инженерно-геологических изысканий / Г.Г. Болдырев, В.А. Барвашов, И.Х. Идрисов, О.В. Хрянина // Вестник ПНИПУ. - 2017. - Т. 8 - № 3. - С. 22-33.
13. Lunne T., Christophersen H.P. Interpretation of cone penetrometer data for offshore sands $/ / 15^{\text {th }}$ Annual OTC in Houston. - TX, 1983. - P. 181-192.

14. Senneset K., Janbu N. Shear strength parameters obtained from static cone penetration tests // ASTM STP 883, Symposium. San Diego, 1984. - P. 41-54.

15. Meigh A.C. Cone penetration testing - methods and interpretation. - London: CIRIA, 1987. - $141 \mathrm{p}$.

16. Mayne P.W. Stress-strain-strength-flow parameters from enhances in-situ tests // International Conference on In-Situ Measurement of Soil Properties and Case Histories. - Bali, Indonesia, 2001. - P. 27-48.

17. Sanglerat G. The penetrometer and soil exploration. - Amsterdam: Elsevier Publishing Company, 1972. - 488 p.

18. Jones G.A., Rust E.A. Piezometer penetration testing CPTU // $2^{\text {nd }}$ European Symposium on Penetration Testing. - Amsterdam, 1982. - V. 2 - P. 607-613.

19. Direct Soil Classification by Static Penetrometer with Special Friction Sleeve / G. Sanglerat, T. Nhim, M. Sejourne, R. Andina // Proc of the First European Symposium on Penetration Testing. Stockholm, 1974. - V. 2.2. - P. 337-344.

20. Kulhawy F.N., Mayne P.H. Manual on estimating soil properties for foundation design. - Palo Alto, USA: Electric Power Research Institute (EPRI) Press, 1990. - $306 \mathrm{p}$.

Поступила 12.02.2019 2.

\section{Информация об авторах}

Латыпов А.И., кандидат технических наук, доцент кафедры общей геологии и гидрогеологии Института геологии и нефтегазовых технологий Казанского (Приволжского) федерального университета.

Яббарова $\boldsymbol{E} . \boldsymbol{H} .$, аспирант кафедры общей геологии и гидрогеологии Института геологии и нефтегазовых технологий Казанского (Приволжского) федерального университета. 
UDC 624.131 .35

\title{
ON INTERPRETATION OF THE DATA OF SOIL CONE PENETRATION TESTS
}

\author{
Airat I. Latypov', \\ airatlat@mail.ru \\ Ekaterina N. Yabbarova', \\ yabbarova.en@mail.ru \\ 1 Kazan (Volga Region) Federal University, \\ 4/5, Kremlevskaya street, Kazan, 420004, Russia.
}

\begin{abstract}
The relevance of the research is caused by the ever-increasing use of the method of cone penetration tests of soils, changing the requirements for design of foundations in modern construction and revealed significant discrepancy of physical and mechanical characteristics of the soils determined using cone penetration tests according to the tables of SP 11-105 and the data of laboratory tests.

The main aim of the research is the comparative analysis between laboratory studies and cone penetration tests in the study area.

Objects: soil basement of the foundations of a residential complex in Kazan, Rodina Street.

Methods: analysis of domestic and foreign experience, cone penetration tests of soils, laboratory studies of physical and mechanical properties of soils, statistical processing of test results.

Results. Using the example of the construction site for a complex of residential 9-25-storey houses in Kazan the authors have shown the impossibility of applying the SP 11-105 tables to determine the mechanical characteristics of a number of soils. This conclusion was made on the basis of processing the results of 125 points of cone penetration tests, passed to a depth of $20 \mathrm{~m}$, drilling of 59 boreholes to a depth of $40 \mathrm{~m}$, as well as laboratory tests of soil samples with determination of strength and strain properties. Comparative analysis of field and laboratory researches for various engineering-geological elements on the study area shown that the values of the strength and strain characteristics of soils obtained using the method of cone penetration test, are significantly overestimated, and the carrying capacity of the piles is underestimated. It is proposed to solve this problem by creating regional building standards in the field of cone penetration tests of soils for Kazan and the Republic of Tatarstan. This will improve the accuracy of engineering and geological surveys and increase the economic profitability of construction.
\end{abstract}

Key words:

Soil, cone penetration test, regional buildings standards, Kazan, Republic of Tatarstan.

\section{REFERENCES}

1. Zharkova N.I. Zakonomernosti formirovaniya inzhenernogeologicheskikh usloviy na territorii g. Kazani. Avtoreferat Kand. nauk [Laws of formation of geotechnical conditions of the city of Kazan. Cand. Diss. Abstract]. Ekaterinburg, 2006. 22 p.

2. Shevelev A.I., Zharkova N.I., Khuzin I.A., Polyakov S.I., Galeev R.K., Serebrennikova I.A., Latypov A.I., Nuriev I.S., Akhiyarova Yu.R., Mukhamedshina M.I. Gidrogeologicheskie i inzhenerno-geologicheskie usloviya goroda Kazani [Hydrogeological and geotechnical conditions of the city of Kazan]. Kazan, Kazan University Publ., 2012. 236 p.

3. Zharkova N.I., Latypov A.I., Shevelev A.I., Khuzin I.A. Sozdanie postoyanno deystvuyushchey modeli geologicheskoy sredy g. Kazani dlya resheniya razlichnykh inzhenerno-geologicheskikh zadach [Development of a permanent geological environment model of Kazan city aimed to solve various engineering-geological problems]. Souremennye problemy gidrogeologii, inzhenernoy geologii i gidrogeoekologii Yeurazii. Materialy Vserossiyskoy konferentsii [International Conference on Modern Problems of Hydrogeology, Geology Engineering and Hydrogeoecology of Eurasia. Proc. of the All-Russian Conference]. Tomsk, TPU Publ., 2015. Vol. II, pp. 329-336.

4. Latypov A.I., Zharkova N.I., Voznesensky E. Zoning of the Kazan City territory by the stability of foundation soil during dynamic impact. Advances and Trends in Engineering Materials and their Applications, 2017, vol. 2017-June, pp. 45-51.

5. SP 22.13330. Osnovaniya zdany $i$ sooruzheny [Soil bases of buildings and structures]. Moscow, Minregion Rossii Publ., 2016. $162 \mathrm{p}$.

6. SP 11-105. Inzhenerno-geologicheskie izyskaniya dlya stroitel stva [Engineering geological site investigations for construction]. Moscow, PNIIIS Gosstroya Rossii Publ., 1997. P. I, 47 p.
7. Ryzhkov I.B., Isaev 0.N. Staticheskoe zondirovanie gruntov [Cone Penetration Testing]. Moscow, ASV Publ., 2010. 496 p.

8. Ziangirov R.S., Kashirskii V.I. Use of static-penetration data to evaluate deformation properties of disperses soils. Soil Mechanics and Foundation Engineering, 2005, vol. 42, no. 1, pp. 15-21. In Rus.

9. Boldyrev G.G. Rukovodstvo po interpretatsii dannykh ispytaniy metodami staticheskogo i dinamicheskogo zondirovaniya dlya geotekhnicheskogo proektirovaniya [Guide to the Interpretation of Test Data by Static and Dynamic Sounding for Geotechnical Design]. Moscow, Prondo Publ., 2017. 476 p.

10. Boldyrev G.G. Numerical modeling of static penetration testing and drilling sending. Geotekhnica, 2016, vol. 4, pp. 58-74. In Rus.

11. Boldyrev G.G., Barvashov V.I., Melnikov A.V. On data interpretation of static probing of soils. Geotehknika, 2016, vol. 5, pp. 10-15. In Rus.

12. Boldyrev G.G., Barvashov V.A., Idrisov I.Kh., Khryanina O.V. Integrated technology of geotechnical survey. Vestnik PNIPU, vol. 8, no. 3, pp. 22-33. In Rus.

13. Lunne T., Christophersen H.P. Interpretation of cone penetrometer data for offsore sands. $15^{\text {th }}$ Annual OTC in Houston. TX, 1983. pp. 181-192.

14. Senneset K., Janbu N. Shear strength parameters obtained from static cone penetration tests. In Proceedings of ASTM STP 883, Symposium. San Diego, 1984. pp. 41-54.

15. Meigh A.C. Cone penetration testing - methods and interpretation. London, CIRIA, 1987. $141 \mathrm{p}$.

16. Mayne P.W. Stress-strain-strength-flow parameters from enhances in-situ tests. International Conference on In-Situ Measurement of Soil Properties and Case Histories. Bali, Indonesia, 2001. pp. 27-48. 
17. Sanglerat G. The penetrometer and soil exploration. Amsterdam, Elsevier Publishing Company, 1972. 488 p.

18. Jones G.A., Rust E.A. Piezometer penetration testing CPTU. $2^{\text {nd }}$ European Symposium on Penetration Testing. Amsterdam, 1982. Vol. 2, pp. 607-613.

19. Sanglerat G., Nhim T., Sejourne M., Andina R. Direct Soil Classification by Static Penetrometer with Special Friction Sleeve. Pro- ceedings of the First European Symposium on Penetration Testing. Stockholm, 1974. Vol. 2.2, pp. 337-344.

20. Kulhawy F.N., Mayne P.H. Manual on estimating soil properties for foundation design. Palo Alto, USA, Electric Power Research Institute (EPRI) Press, 1990. 306 p.

Received: 12 February 2019.

\section{Information about the athors}

Airat I. Latypov, Cand. Sc., associate professor, Kazan (Volga Region) Federal University.

Ekaterina N. Yabbarova, assistant, Kazan (Volga Region) Federal University. 